sát các chỉ số Albumin-Bilirubin ở bênh nhân xơ gan có ung thư biểu mô tế bào gan với số lượng 224 BN và có kết luân như sau: Phân điểm ALBI tăng dần theo mức độ nặng của UTBMTBG theo phân loại Child-Pugh và phân loại Barcelona.

\section{TÀI LIẸU THAM KHẢO}

1. Bosch, F.X., et al. Primary liver cancer: worldwide incidence and trends. Gastroenterology, 2004. 127(5 Suppl 1): p. S5-s16.

2. Johnson, P.J., et al., Assessment of liver function in patients with hepatocellular carcinoma: a new evidence-based approach-the ALBI grade. J Clin
Oncol, 2015. 33(6): p. 550-8.

3. Toyoda, $\mathbf{H}_{\text {., }}$ et al., Long-term impact of liver function on curative therapy for hepatocellular carcinoma: application of the ALBI grade. $\mathrm{Br}$ J Cancer, 2016. 114(7): p. 744-50.

4. Gui, B., et al., Assessment of the AlbuminBilirubin (ALBI) Grade as a Prognostic Indicator for Hepatocellular Carcinoma Patients Treated With Radioembolization. Am J Clin Oncol, 2018. 41(9): p. 861-866.

5. Wang, Y.Y., et al., Albumin-bilirubin versus ChildPugh score as a predictor of outcome after liver resection for hepatocellular carcinoma. The British journal of surgery, 2016. 103.

\title{
ĐĂC ĐIỂM LÂM SÀNG VÀ CHẤT LƯợNG CUộC SỐNG CỦA NGƯỜI BÊ̂NH ĐộNG KINH TẠI TRUNG TÂM THẦN KINH, BÊ̂NH VIỆN BACCH MAI NĂM 2020 - 2021
}

\section{TÓM TẮT}

Nghiên cứu mô tả cắt ngang thực hiện trên 385 bênh nhân tại Trung tâm Thẩn kinh - Bệnh viện Bach Mai từ tháng 12/2020 đến tháng 08/2021. Mục tiểu: Mô tả đắc điểm lâm sàng và chất lượng cuộc sống của người bệnh động kinh tại Trung tâm Thần kinh - Bệnh viện Bạch Mai. Số liệu thu thập được từ bệnh án nghiên cứu về chất lượng cuộc sống. Số bệnh nhân tuổi $\geq 40$ chiếm đa số với $54,3 \%$, tuổi trung bình là $44,49 \pm 17,89$. Nam giới chiếm tỷ lệ cao hơn nữ giới (65,2\% so với $34,8 \%) ;$ Trình độ học vấn: Từ Trung học phổ thông chiếm đa số với 55,9\%. Hôn nhân: đa sổ người bệnh có gia đình với 64,2\%; Kinh tễ: Hỗ không nghèo: 95,3\%; Hộ nghèo/ Cận nghèo: 4,7\%; Ớ thành thị cao hớn nông thôn (53,2\% so với $46,8 \%)$. Nghề nghiêp: cán bô công nhân viên $(61 \%)$, nông dân $(28,1 \%)$; Hoàn cảnh sống cùng gia đình chiếm đa số với $96,9 \%$; Có bảo hiểm y tế chiếm đa số với $81,3 \%$; thời gian mắc bệnh <5 năm $(74 \%) ;>5$ năm (26\%). Hoàn cảnh xảy ra cớn chiếm tỷ lệ cao nhất khi đang làm việc (32,5\%). Đặc điểm người bệnh khi có cơn: Dấu hiệu báo trước cởn chiếm đa số là không có triệu chứng $(51,9 \%)$, nhức đâu $(20,5 \%)$, tê bì chân tay $(11,4 \%)$. Tần số cơn > 1 cơn/ngày $(57,1 \%),>1$ cơn /tháng nhưng không > 1 cơn/tuần $(14,3 \%)$, > 1 cơn/tuân $(13,8 \%), \geq 1$ cơn/ năm $(11,7 \%)$. không có cơn/năm qua chỉ 3,1\%. Tổng điểm QOLIE trung bình: $57,71 \pm 10,51$; Mức độ CLCS kém chiếm tỷ lệ cao nhất là $50,6 \%$.

Tư khóa: động kinh, chất lượng cuộc sống, người bệnh, bệnh viện.

${ }^{1}$ Bệnh viện Bạch Mai

2 Trường Đai hoc Thăng Long

Chịu trách nhiệm chính: Bùi Thị Liên

Email: lientbvn@gmail.com

Ngày nhân bài: 18.10.2021

Ngày phản biên khoa hoc: 14.12.2021

Ngày duyệt bài: 22.12.2021

\section{CLINICAL CHARACTERISTICS AND QUALITY OF LIFE OF EPILEPSY PATIENTS AT CENTER OF NEUROLOGY - BACH MAI HOSPITAL, 2020 - 2021}

SUMMARY

A cross-sectional descriptive study on 385 patients at Centre of Neurology - Bach Mai Hospital from December 2020 to August 2021. Objective: describe the clinical characteristics and quality of life of epilepsy patients at Centre of Neurology - Bach Mai hospital. The prevalence of men was higher than women $(65.2 \%$ compared to $34.8 \%)$, average age: $44.49 \pm$ 17,89. Education level: above high school education accounts for the highest: $55.9 \%$. Marriage status: married: $64.2 \%$. Socioeconomic status: non-poor households: $95.3 \%$; poor/near poor households: $4.7 \%$. Resedency area: urban area was higher than rural area (53.2\% compared to $46.8 \%)$. Occupation: civil servant $(61 \%)$, farmer $(28.1 \%)$. The prevalence of patients have health insurance was $81.3 \%$; disease duration less than 5 years accounted for $74 \%$; $>5$ years. Onset time: working (32.5\%), sleeping $(26.5 \%)$, heavy labor/fatigue $(17.7 \%)$, walking (8.8\%). Onset symptom: without symptoms $(51.9 \%)$, headache $(20.5 \%)$, numbness in limbs $(11.4 \%)$. Frequency of attacks $>1$ attack per day $(57.1 \%)$, only $3,1 \%$ of patients have free seizure in a year. Total average QOLIE score: $57.71 \pm 10.51$, in which low level - quality of life accounted for highest prevalence $(50,6 \%)$.

Keywords. epilepsy, quality of life, patient, hospital.

\section{I. ĐĂT VẤN ĐỀ}

Động kinh (ĐK) là một tình trạng bệnh lý của não dọo nhiều nguyên nhân khác nhau gây ra với bệnh cảnh rất phức tạp và đa dạng. Bệnh có thể gặp ở mọi lứa tuổi, mọi giới. Theo thống kê của Tổ chức $Y$ tế Thế giới (WHO), tỷ lệ người mắc 
bệnh động kinh trên thế giới khoảng 0,5\% dân số, thay đổi tùy theo từng quốc gia, từng vùng, từng dân tộc, như ở Pháp và ở Mỹ là khoảng 0,85\%; Canada là 0,6\%. ${ }^{6}$ Người bệnh ĐK thường tự ti, cô lập với xã hội, lo lắng và hay bị trầm cảm hơn. Người bệnh ĐK cũng có tỷ lệ thất nghiệp cao hơn, tỷ lệ kết hôn thấp hơn so với người khỏe mạnh. Với tính chất và bệnh cảnh phức tạp, đa dạng, bệnh động kinh đã có những ảnh hưởng không nhỏ đến chất lượng cuộc sống của người bệnh. Do đó, xem xét các đắc điểm lâm sàng và đánh giá CLCS bệnh nhân động kinh là việc cần thiết nhằm đưa ra những giải pháp hỗ trợ, nâng cao CLCS của người bệnh ĐK. Đó là lý do đề tài "Chất lượng cuộc sống của bệnh nhân động kinh và một số yếu tố liên quan tại
Trung tâm Thần kinh - Bệnh viện Bạch Mai" được tiến hành nhằm mục tiêu sau: Mô tả đặc điểm lâm sàng và chất lượng cuộc sống của người bệnh động kinh tại Trung tâm Thần kinh bệnh viện Bạch Mai.

\section{II. ĐỐI TƯợNG VÀ PHƯƠNG PHÁP NGHIÊN CỨU}

1.Tiêu chuẩn lựa chọn: Người bệnh được chẩn đoán mắc bệnh động kinh đang điều trị ngoại trú tại Khoa Thần kinh - Bệnh viện Bạch Mai. Thời gian: 12/2020 đến tháng 08/2021

2. Thiết kế nghiên cứu: Nghiên cứu mô tả cắt ngang

3. Cõ̃ mẫu: 385 bệnh nhân động kinh tại Khoa Thần kinh - Bệnh viện Bạch Mai.

\section{KẾT QUẢ NGHIÊN CỨU}

\section{1. Đặc điểm chung của đối tượng nghiên cứu}

Bảng 1. Đặc điểm chung của đôî́ tượng nghiên cứu

\begin{tabular}{|c|c|c|c|}
\hline \multicolumn{2}{|c|}{ Biến số nghiên cứu } & n (385) & Tỷ lệ (\%) \\
\hline \multirow{2}{*}{ Giới } & Nam & 251 & 65,2 \\
\hline & Nũ̃ & 134 & 34,8 \\
\hline \multirow{2}{*}{$\begin{array}{l}\text { Tuối của đối tượng } \\
\text { nghiên cứu }\end{array}$} & $<40$ & 176 & 45,7 \\
\hline & $\geq 40$ & 209 & 54,3 \\
\hline Tuối trung bình & \multicolumn{3}{|c|}{ 44,49 $\pm 17,89$ (18-87 tuối) } \\
\hline \multirow{2}{*}{$\begin{array}{l}\text { Trình độ học vấn của } \\
\text { đối tượng nghiên cứu }\end{array}$} & Dưới THPT & 170 & 44,1 \\
\hline & Từ THPT trở lên & 215 & 55,9 \\
\hline \multirow{4}{*}{$\begin{array}{l}\text { Nghề nghiệp của đối } \\
\text { tượng nghiên cứu }\end{array}$} & Viên chức/ Công nhân & 235 & 61 \\
\hline & Nông dân & 108 & 28,1 \\
\hline & Buôn bán & 28 & 7,3 \\
\hline & Khác (SV, thất nghiệp,...) & 14 & 3,6 \\
\hline \multirow{2}{*}{ Hôn nhân } & Có vợ/ chồng & 247 & 64,2 \\
\hline & Ly hôn/góa/ độc thân & 41 & 35,8 \\
\hline \multirow[t]{3}{*}{ Hoàn cảnh sống } & Bố mẹ/ Vợ chồng/ Con/ Cháu & 372 & 96,9 \\
\hline & Một mình không có người chăm sóc & 8 & 2,1 \\
\hline & Một mình có thuê người chăm sóc & 4 & 1,0 \\
\hline \multirow{2}{*}{ Nơi sống } & Thành thị & 205 & 53,2 \\
\hline & Nông thôn & 180 & 46,8 \\
\hline \multirow{2}{*}{ Kinh tế } & Hộ nghèo/cận nghèo & 18 & 4,7 \\
\hline & Không nghèo & 367 & 95,3 \\
\hline \multirow{2}{*}{ BHYT } & Có & 313 & 81,3 \\
\hline & Khôna & 72 & 187 \\
\hline
\end{tabular}

Nhận xét: Tỷ lệ nam cao hơn nữ $(65,2 \%$ so với 34,8\%). Chiếm tỷ lệ cao nhất ở nhóm tuổi $\geq$ 40, Tuổi trung bình: 44,49 $\pm 17,89$ năm. Trình độ học vấn: Dưới THPT $(44,1 \%)$ và từ THPT trở lên chiếm $55,9 \%$. Nghề nghiệp chủ yếu là công nhân viên chức (61\%). Đối tượng có BHYT chiếm tỷ lệ $81,3 \%$. Tình trạng kết hôn có vợ, chồng chiếm tỷ lệ cao hơn tình trạng lỳ hôn/góa/độc thân (64,2\% so với 35,8\%). Sống cùng Bố mẹ/ Vợ chồng/con/cháu chiếm tỷ lệ cao nhất $(96,9 \%)$. Tình trạng kinh tế Hộ không nghèo chiếm tỷ lệ cao nhất: 95,3\%. Hộ nghèo/cận nghèo chiếm tỷ lệ $4,7 \%$. Khu vực sống ở thành thị cao hơn nông thôn $(53,2 \%$ so với 46,8\%).

2. Đặc điểm lâm sàng của người bệnh động kinh

Bảng 2 .Đặc điểm về tần số cơn động kinh của nhóm nghiên cứu

\begin{tabular}{|c|c|c|}
\hline Biến số nghiên cứu & $\mathbf{N}$ & $\mathbf{\%}$ \\
\hline Không có cơn trong năm qua & 12 & 3,1 \\
\hline$\geq 1$ cơn/ năm & 45 & 11,7 \\
\hline
\end{tabular}




\begin{tabular}{|c|c|c|}
\hline $\begin{array}{c}\text { > } 1 \text { cơn/ tháng nhưng không } \\
>1 \text { cơn/ tuần }\end{array}$ & 55 & 14,3 \\
\hline$>1$ cơn/ tuần & 53 & 13,8 \\
\hline$>1$ cơn/ ngày & 220 & 57,1 \\
\hline
\end{tabular}

Nhân xét: Chiếm tỷ lệ cao nhất là có tân số cơn > 1 cơn/ ngày (57,1\%). Sau đó đến tân số cơn $>1$ cơn/ tháng nhưng không > 1 cơn/ tuân $(14,3 \%)$, tiếp đến là NB có $>1$ cơn/ tuân $(13,8 \%)$, tiếp đến $\geq 1$ cơn/ năm $(11,7 \%)$. Thấp nhất là không có cớn trong năm qua (chiếm 3,1\%).

Bảng 3. Dâu hiệu báo trước cớn ở NB động kinh

\begin{tabular}{|c|c|c|c|}
\hline Dấu hiệu báo trước cơn & Cục bộ (n=152) & Toàn thể (n=228) & Chung \\
\hline Không có triệu chứng & $74(48,7 \%)$ & $121(53,1 \%)$ & $200(51,9 \%)$ \\
\hline Nhức đầu & $28(18,4 \%)$ & $51(22,4 \%)$ & $79(20,5 \%)$ \\
\hline Tê bì chân tay & $26(17,1 \%)$ & $18(7,9 \%)$ & $44(11,4 \%)$ \\
\hline Nhìn mờ & $7(4,6 \%)$ & $15(6,6 \%)$ & $22(5,7 \%)$ \\
\hline Hoa mắt, chóng mặt & $5(3,3 \%)$ & $12(5,3 \%)$ & $17(4,4 \%)$ \\
\hline Rối loạn ngôn ngữ & $2(1,3 \%)$ & $5(2,2 \%)$ & $7(1,8 \%)$ \\
\hline Khác (đau bụng, buồn nôn, sợ hãi,,..$)$ & $6(3,9 \%)$ & $11(4,8 \%)$ & $17(4,4 \%)$ \\
\hline
\end{tabular}

Nhân xét: chiếm tỷ lê cao nhất là không có triêu chứng (51,9\%), rồi đến nhức đầu (20,5\%), tê bì chân tay $(11,4 \%)$, nhìn mờ $(5,7 \%)$, hoa mắt chóng mặt và một số dấu hiệu khác đồng chiếm $(4,4 \%)$. Thấp nhất là dấu hiệu rối loạn ngôn ngữ $(1,8 \%)$.

\section{Chất lượng cuộc sống của bệnh nhân động kinh}

Bảng 4. Tổng điểm về chât lượng cuộc sống của người bệnh động kinh theo QOLIE - 31

\begin{tabular}{|c|c|c|}
\hline Yếu tố & TB \pm SD & Min-Max \\
\hline Lo lắng cơn co giật & $42,51 \pm 15,82$ & $17,32-100$ \\
\hline Chất lượng sống tống thế & $61,14 \pm 16,31$ & $10,0-95,0$ \\
\hline Cảm giác dề chịu & $61,29 \pm 11,93$ & $32,0-84,0$ \\
\hline Năng lượng/ mệt mỏi & $47,19 \pm 13,53$ & $15,0-80,0$ \\
\hline Chức năng nhận thức & $75,78 \pm 14,81$ & $16,67-100$ \\
\hline Ánh hưởng của thuốc & $64,40 \pm 22,62$ & $0,0-100$ \\
\hline Chức năng xã hội & $40,51 \pm 16,29$ & $4,0-90,0$ \\
\hline Tống điếm QOLIE & $57,71 \pm 10,51$ & $19,34-92,08$ \\
\hline
\end{tabular}

Nhận xét: Bảng 4 cho biết; Tổng điểm về lo lắng cớn co giật là 42,51 $\pm 15,82 ;$ Tổng điểm về chất lượng sống tổng thể là $61,14 \pm 16,31 ;$ Tổng điểm về cảm giác dễ chịu là $61,29 \pm 11,93$; Tổng điểm về năng lượng/ mệt mỏi là $47,19 \pm 13,53$; Tổng điểm về chức năng nhận thức là 75,78 \pm 14,81 , Tổng điểm về ảnh hưởng của thuốc là $64,40 \pm 22,62$; Tổng điểm về chức năng xã hội là $40,51 \pm 16,29$. Tổng điểm trung bình của tất cả các yếu tố là $57,71 \pm 10,51$.

Bảng 5. Mức độ CLCS theo thang QOLIE-31

\begin{tabular}{|c|c|c|}
\hline Mức độ CLCS & Số lượng & Tỷ lệ \% \\
\hline Chất lượng cuộc sống tốt & 31 & 8,1 \\
\hline $\begin{array}{c}\text { Chất lượng cuộc sống trung } \\
\text { bình }\end{array}$ & 159 & 41,3 \\
\hline Chất lượng cuộc sống kém & 195 & 50,6 \\
\hline Tống & $\mathbf{3 8 5}$ & $\mathbf{1 0 0}$ \\
\hline
\end{tabular}

Nhận xét: chiếm tỷ lế cao nhất là chất lượng cuộc sống kém với 50,6\%. Giảm dần đến chất lượng cuộc sống trung bình là 41,3\%. Chất lượng cuộc sông tốt chiếm 8,1\%.

\section{BÀN LUÂ̂N}

Đặc điểm của đối tượng nghiên cứu: Bảng 1 cho biết, tỷ lệ nam cao hơn nữ $(65,2 \%$ so với $34,8 \%)$, kết quả này cũng tương đồng với nghiên cứu tác giả Nguyễn Anh Dũng thì các bệnh nhân trong nghiên cứu này có tỷ lệ nam/ nữ lần lượt là $61,6 \%$ và $38,4 \%{ }^{2}$

Về nhóm tuổi, cao nhất ở nhóm tuổi $\geq 40$, tuổi trung bình của các bệnh nhân nghiên cứu là $44,49 \pm 17,89$, tuổi nhỏ nhất là 18 (theo điều kiện lựa chọn bệnh nhân) và lớn nhất là 87 tuổi. So với nghiển cứu cũng trên các bệnh nhân động kinh là người trưởng thành của tác giả Nguyễn Anh Dũng thì các bệnh nhân trong nghiên cứu này có độ tuổi nhiều hơn là $42,5 \pm 15,8 .^{2}$

Về trình độ học vấn, THPT trở lên chiếm $55,9 \%$, chưa kể đến còn những bênh nhân không đi học, hoặc là học hết tiểu học hay trung học cơ sở chiếm 44,1\%. Kết quả này tương đồng với kết quả nghiên cứu chất lượng cuộc sống của người bệnh động kinh của tác giả Nguyễn Thị Hồng Phấn có trình độ học vấn từ mức tốt nghiệp THPT trở lên so với trình độ dưới THPT lần lượt là $65,9 \%$ và $34,1 \%{ }^{4}$

Về nghề nghiệp, nói lên sự khó khăn của bênh nhân động kinh trong viêc học nghề và tìm cho mình một công việc thích hợp. Theo các nghiên cứu dịch tễ học thì số bệnh nhân động kinh phát bệnh trước 6 tuổi chiếm $60 \%$, đồng 
thời khoảng 85 \% bệnh nhân động kinh ở các nước đang phát triển không được điêu trị hoặc điều trị không đúng cách².

Tình trạng kinh tế hộ không nghèo chiếm tỷ lệ cao nhất: 95,3\%. Hộ nghèo/cận nghèo chiếm tỷ lệ 4,7\%. Tình trạng kinh tế là một yếu tố quan trọng ảnh hưởng đến CLCS của bệnh nhân động kinh. Đây là kết quả của nhiều nghiên cứu. Ớ nghiên cứu của Nguyễn Thị Hồng Phấn những bệnh nhân có mức thu nhập cao có điểm CLCS là 69.14, cao hơn 13.46 điểm so với những bệnh nhân có mức thu nhập thấp (55.68 điểm). Sự chênh lệch này có ý nghĩa thống kê với độ tin cậy $99 \%$, khi $p=0,000{ }^{4}$

Khu vực sống, ở thành thị cao hơn nông thôn (53,2\% so với $46,8 \%$, do bệnh viện Bạch Mai là bệnh viện lớn của khu vực phía Bắc, người dân nội thành dễ dàng tìm đển khám và điều trị. Kết quả này ngược với kết quả của tác giả Nguyễn Thị Hồng Phấn, phần nhiều các bệnh nhân trong nghiên cứu lại sống ở nông thôn với $60.6 \%$, còn các bệnh nhẩn sống ở khu vực thành thị ít hơn, chiếm $30,4 \%{ }^{4}$

Bảng 2 cho thấy, NB có tần số cơn $>1$ cơn/ ngày $(57,1 \%)$; cơn $>1$ cơn/ tháng nhưng không $>1$ cơn/ tuần $(14,3 \%)$, tiếp đến là NB có $>1$ cơn/ tuân $(13,8 \%)$, tiếp đến $\geq 1$ cơn/năm $(11,7 \%)$, không có cơn trong năm qua (chiếm $3,1 \%$ ). Kết quả này ngược với kết quả của tác giả Trần Nguyên Ngọc, số bệnh nhân động kinh có cơn càng dày chiếm số lượng càng ít dần. Cụ thể là số bênh nhân không có cơn trong năm qua chiếm 24,7\%, $\geq 1$ cơn/năm nhưng không quá 1 cơn/tháng chiếm 40,7\%, số bệnh nhân có tần số cơn động kinh $\geq 1$ cơn/tháng nhưng không quá 1 cơn/tuần chiếm 19,3\%, số bệnh nhân có tần số cơn động kinh > 1 cơn/tuần nhưng không quá 1 cơn/ngày chiếm $7,7 \%$, số bệnh nhân có tần số cơn động kinh > 1 cơn/ngày chiếm $2,7 \%$. $^{3}$

Bảng 3 cho biết, NB không có triệu chứng $(51,9 \%)$, nhức đầu $(20,5 \%)$, tê bì chân tay $(11,4 \%)$, nhìn mờ $(5,7 \%)$, hoa mắt chóng mặt và một số dấu hiệu khác đồng chiếm $(4,4 \%)$, rối loạn ngôn ngữ (1,8\%). Nghiên cứu của chúng tôi cho thấy động kinh thường xảy ra tự nhiên, không có dấu hiệu báo trước (51,9\%). Kết quả này tương đồng với kết quả Nguyễn Anh Dũng là $52,0 \%{ }^{1}$. Cơn xảy ra đột ngột nên luôn tồn tại nguy cơ cao và rất khó đề phòng cho sự an toàn của người bệnh. Bảng 4 cho biết, điểm CLCS tổng thể của bệnh nhân động kinh tại Trung tâm là $57,71 \pm 10,51$. Trong các thành phần cấu tạo nên CLCS thì điểm cao nhất là Nhận thức $(75,78$ điểm), điểm thấp nhất là Chức năng xã hội (40,51 điểm) và Lo cơn động kinh (42,51 điểm). Các tác giả tổng hợp khái niệm của họ rằng CLCS của con người không bị ảnh hưởng trực tiếp bởi một bệnh lý mãn tính mà phản ảnh những vấn đề và những mối liên quan tạo ra do sự giảm hoặc mất của các nguồn lực cá nhân, xã hội và kinh tế (ví dụ: sự xấu đi của các vấn đề trong gia đình, những thay đổi nghề nghiệp, mất thu nhập, giảm lòng tự trọng và khả năng kiểm soát). Ngoài ra, việc sử dụng thuốc kháng động kinh cũng chính là một trong các nguyên nhân gây suy giảm chất lượng cuộc sống. Người bệnh rõ ràng mất thêm khoản chi phí khi sử dụng thuốc và phải chịu đựng những tác dụng phụ do thuốc gây ra như là mệt mỏi, rối loạn trí nhớ, buồn ngủ, hồi hộp, rối loạn hành vi... Và nếu chưa gặp những vấn đề đó thì họ cũng lo lắng rằng nó sẽ xảy ra. Sự xuất hiện các rào cản về tâm lý xã hội và y tế thúc đẩy việc các bệnh nhân động kinh ít có cơ hội học hành, kết quả học tập ở trường thấp hơn, khó tìm kiếm việc làm, thu nhập thấp, ít cơ hội kết hôn. ${ }^{7}$ Tại bảng 5 cho thấy, chiếm tỷ lệ cao nhất là chất lượng cuộc sống kém với $50,6 \%$. Giảm dần đến chất lượng cuộc sống trung bình là $41,3 \%$. Chất lượng cuộc sông tốt chiếm 8,1\%.

\section{KẾT LUẬN}

- Có tần số cớn > 1cơn/ngày $57,1 \%$; có > 1cơn/ tháng 14,3\%; có $>1$ cơn/tuần $13,8 \% ; \geq 1$ cơn/ năm 11,7\%; không có cơn trong năm qua chiếm 3,1\%.

- Về dấu hiệu báo trước: không có triệu chứng $51,9 \%$, nhức đầu $20,5 \%$, tê bì chân tay $11,4 \%$, nhìn mờ $5,7 \%$, hoa mắt chóng mặt và một số dấu hiệu khác đồng chiếm 4,4\%, rối loạn ngôn ngữ 1,8\%.

- Tổng điểm QOLIE của các đối tượng nghiên cứu là 57,71 điểm. Chất lượng cuộc sống kém: $50,6 \%$. Chất lượng cuộc sống TB: $41,3 \%$. Chất lượng cuộc sống tốt: 8,1\%.

\section{TÀI LIÊUU THAM KHẢO}

1. Nguyễn Anh Dũng (2008), Luận văn thạc sỹ học "Nghiên cứu một số đặc điểm lâm sàng và hình ảnh học của động kinh ở người trưởng thành tại khoa Thần kinh Bệnh viện Bạch Mai, Trường Đaai hoc $Y$ Hà Nội

2. Tố Hồng Đức và CS (2008), Phân Loai cơn động kinh trẻ em tại Bệnh viện Nhi đồng I thành phố Hố Chí Minh, Y học thành phố Hồ Chí Minh, 12(3), tr. $172-175$.

3. Trân Nguyên Ngọc (2012). Nghiên cứu chất lượng sông bệnh nhân động kinh ở người lớn tại thành phố Đà Nẵng. Bệnh viện tâm thần Đà Nẵng]

4. Nguyển Thị Hông Phấn (2020), Luận văn thạc 
sĩ y học, "Chất lượng cuộc sống và các yếu tố ảnh hưởng đến chất lương cuốc sống ở bênh nhân động kinh Ikuko Laccheo, Elizabeth Ablah, Robin Heinrichs, Toni Sadler, Lyle 5. Baade, Kore Liow (2008), Assessment of quality of life among the elderly with epilepsy, Epilepsy and Behavior, 12, pp. $257-261$

5. Goodridge và S. D. Shorvon (1983). Epileptic seizures in a population of 6.000. Demography, diagnosis and classification. B-M-J 287
6. M. Rathor, M. Shahar, A. Omar et al (2017). Assessment of Knowledge, attitude and practices of Epilepsy Patients towards their illness and treatment in a tertiary care hospital in Kuantan Pahang Malaysia. Bangladesh. Journal of Medical Science, 16(14):545-553.

7. Mukadder Monl, laoglu Injuries in Patients with Epilepsy and Some Factors Associated with Injury -ncbi

\section{XÂY DỰNG MÔ HÌNH DƯ BÁO CHI PHÍ CHO ĐIỀU TRI BÊNNH SUY TIM DỰA TRÊN DỮ LIẾU THANH TOÁN BẢO HIỂM Y TẾ TOÀN QUỐC GIÁI ĐOẠN 2017 - 2018}

\section{TÓM TẮT}

Hiện nay, bệnh suy tim là một vấn đề lớn về y tế và kinh tế đang gia tăng trên toàn thế giới. Chí phí điều trị suy tim đã được thực hiện ở một số quốc gia trên thế giới tuy nhiên chưa có nghiên cứu dự báo chi phí điêu trị suy tim. Phân tích chi phí (CP) trực tiếp y tế (TTYT) trong điều trị suy tim trên mẫu 111.926 người bệnh suy tim dựa trên dữ liệu hồi cứu tại Bảo hiểm xã hội Việt Nam trong giai đoạn 2017 - 2018, đề tài ghi nhận với độ tuổi trung bình $69,71 \pm 15,18$; tỷ lệ nam: nữ là 1: 1,30; số ngày điều trị trung bình tại bệnh viện $11,99 \pm 13,64$ ngày, các yếu tố có liên quan đến tổng chi phí điều trị bao gồm sử dụng thủ thuật phẫu thuật, tuổi người bệnh, giới tính nam, số ngày điều trị, cấp cứu, nội chuyển viện, có tiểu đường, lượt ngoại trú. Mô hình hồi quy tuyến tính đa biến thể hiển mối liên hệ tổng hợp của các yếu tố liên quan đến tổng chi phí điều trị suy tim được xây dựng với $\mathrm{R}^{2}$ hiệu chỉnh là $0,574(\mathrm{p}<0,05)$ và có dang như sau:

LN (Tông chi phí) = 14,503 +0,557 * TTPT + 0,001* Tuôi + 0,053* Nam + 0,045* Số ngày điều tri $+0,095 *$ Cấp cứu $+0,067 *$

Nội chuyên viên + 0,051 * Có tiểu đường + $0,104 *$ Lươt ngoai trú

Tư khóa: Suy tim, chi phí điểu trị, Bảo hiểm xã hội Việt Nam, mô hình, dự báo

\section{SUMMARY \\ CONTRUCT A FORECAST MODEL OF TREATMENT COST FOR HEART FAILURE BASED ON VIETNAMESE HEALTH INSURANCE PAYMENT DATA IN 2017 - 2018 PERIOD}

${ }^{1}$ Đại học Y Dượ TP Hồ Chí Minh

${ }^{2}$ Bảo hiểm xã hội Việt Nam

Chịu trách nhiệm chính: Nguyễn Thị Thu Thủy

Email: nguyenthuthuy@ump.edu.vn

Ngày nhận bài: 18.10.2021

Ngày phản biên khoa hoc: 14.12.2021

Ngày duyệt bài: 21.12.2021
Nguyễn Bá Phát ${ }^{1}$, Nguyễn Ngọc Mai Trúc ${ }^{1}$,
Trần Tiến Hưng ${ }^{2}$, Nguyễn Thị Thu Thuỷ ${ }^{1}$

Currently, heart failure is a major growing health and economic problem worldwide. Treatment cost of heart failure has been analyzed in a number of countries in the world, however where there are no studies predicting duration of treatment failure. Analysis of direct medical costs (CP) during treatment on a sample of 111,926 heart failure patients based on data of Vietnam Social Security in the period 2017 2018 , the study noted with the middle age $69.71 \pm$ 15.18; the male: female ratio is 1 : 1.30 ; average number of days in hospital $11.99 \pm 13.64$ days, factors related to total cost include using technical algorithm, patient age, male gender, number of days value, level up, library of the content, have a small path, extructs. The multivariable computational regression model showing the aggregate relationship of factors related to the total time to adjust the value was built with adjusted R2 of 0.574 ( $p<0.05)$ and has the following form :

LN (Direct medical costs) $=14.503+$

$0.557 *$ Surgical procedures $+0.001 *$ age

$+0.053 *$ male $+0.045 *$ Number of

treatment days $+0.095 *$ emergency +

$0.067 *$ Hospitalization $+0.051 *$ Diabetes $+0.104 *$ Outpatient visits

Keywords: Heart failure, treatment costs, Vietnam Social Insurance.

\section{I. ĐẶT VẤN ĐỀ}

Suy tim là một hội chứng lâm sàng phức tạp do rối loạn cấu trúc hoăc chức năng của tim, làm suy giảm quá trình đổ đầy hoặc tống máu vào tâm thất đối với hệ tuần hoàn [1]. Bệnh suy tim ảnh hưởng đăcc biệt đến người cao tuổi với tỉ lệ $80 \%$ nhập viện liển quan đến bệnh suy tim và $90 \%$ trường hợp tử vong liên quan đến bệnh suy tim xảy ra ở những bệnh nhân từ 65 tuổi trở lên [2]. Suy tim là một vấn đề lớn về y tế và kinh tế 